\title{
Tocotrienol-Rich Fraction from Rice Bran Demonstrates Potent Radiation Protection Activity
}

\author{
Kimberly J. Krager, ${ }^{1,2}$ E. Nathalie Pineda, ${ }^{2}$ Sujay V. Kharade, ${ }^{2}$ \\ Mary Kordsmeier, ${ }^{3}$ Luke Howard, ${ }^{3}$ Philip J. Breen, ${ }^{2}$ Cesar M. Compadre, ${ }^{2}$ \\ Martin Hauer-Jensen, ${ }^{1,2,4}$ and Nukhet Aykin-Burns ${ }^{1,2}$ \\ ${ }^{1}$ Division of Radiation Health, University of Arkansas for Medical Sciences, 4301 West Markham, No. 522-10, \\ Little Rock, AR 72205, USA \\ ${ }^{2}$ Department of Pharmaceutical Sciences, University of Arkansas for Medical Sciences, 4301 West Markham, No. 522-10, \\ Little Rock, AR 72205, USA \\ ${ }^{3}$ Department of Food Science, University of Arkansas, Fayetteville, AR 72704, USA \\ ${ }^{4}$ Surgical Service, Central Arkansas Veterans Healthcare System, Little Rock, AR 72205, USA
}

Correspondence should be addressed to Nukhet Aykin-Burns; naykinburns@uams.edu

Received 26 February 2015; Accepted 18 May 2015

Academic Editor: Kailash Manda

Copyright (C) 2015 Kimberly J. Krager et al. This is an open access article distributed under the Creative Commons Attribution License, which permits unrestricted use, distribution, and reproduction in any medium, provided the original work is properly cited.

\begin{abstract}
The vitamin E analogs $\delta$-tocotrienol (DT3) and $\gamma$-tocotrienol (GT3) have significant protective and mitigative capacity against the detrimental effects of ionizing radiation (IR). However, the expense of purification limits their potential use. This study examined the tocotrienol-rich fraction of rice bran (TRFRB) isolated from rice bran deodorizer distillate, a rice oil refinement waste product, to determine its protective effects against IR induced oxidative damage and $\mathrm{H}_{2} \mathrm{O}_{2}$. Several cell lines were treated with tocotrienols or TRFRB prior to or following exposure to $\mathrm{H}_{2} \mathrm{O}_{2}$ or IR. To determine the radioprotective capacity cells were analyzed for morphology, mitochondrial bioenergetics, clonogenic survival, glutathione oxidation, cell cycle, and migration rate. TRFRB displayed similar antioxidant activity compared to pure tocotrienols. Cells pretreated with TRFRB or DT3 exhibited preserved cell morphology and mitochondrial respiration when exposed to $\mathrm{H}_{2} \mathrm{O}_{2}$. Oxidized glutathione was decreased in TRFRB treated cells exposed to IR. TRFRB reversed mitochondrial uncoupling and protected cells migration rates following IR exposure. The protective antioxidant capacity of TRFRB treated cells against oxidative injury was similar to that of purified DT3. TRFRB effectively protects normal cells against IR induced injury suggesting that rice bran distillate may be an inexpensive and abundant alternate source.
\end{abstract}

\section{Introduction}

Radiation is commonly used in the treatment of a wide range of malignancies. More than $50 \%$ of cancer patients receive radiotherapy alone or in combination with chemotherapy or surgery in order to achieve local or regional control of their malignancies. Although ionizing radiation (IR) is very effective in killing cancer cells, patients continue to suffer from acute and chronic adverse side effects that limit the therapeutic window for radiotherapy [1]. In addition, significant growth in nuclear power production and radionuclide usage increases the risk of radiation exposure to large populations.
Thus, there is a growing need for a safe and effective radioprotector/radiomitigator compound that will minimize the side effects of radiotherapy on normal tissues and reduce the morbidity and mortality from radiation exposure due to accidents or terrorism.

IR exposure causes significant increases in generation of reactive oxygen and nitrogen species (ROS/RNS), such as superoxide, hydrogen peroxide $\left(\mathrm{H}_{2} \mathrm{O}_{2}\right)$, and peroxynitrite. Alterations in redox homeostasis caused by these reactive species damage the DNA and intracellular compartments leading to perturbations in biochemical reactions and critical pathways in both the short and long term following IR 
exposure [2-7]. However studies using various antioxidants to counteract the adverse effects of IR in normal tissues were not fruitful, providing only partial protection $[8,9]$. Tocotrienols, especially the $\gamma$ - and $\delta$-vitamers, are among the few most promising compounds [10-15] and have shown striking effects in protecting against radiation damage. A single injection of $\delta$-tocotrienol (DT3) has a dose reduction factor (DRF) of 1.27 as a radioprotectant and 1.1 as a radiomitigator, while $\gamma$-tocotrienol (GT3) has a DRF of 1.29 as a radioprotector [15]. In addition, these tocols are nontoxic at effective doses [16]. Studies suggest numerous mechanisms by which GT3 and DT3 exert their radioprotective effects, including the enhancement of eNOS activity via regulation of tetrahydrobiopterin availability and prevention of DNA damage to hematopoietic stem and progenitor cells via stimulation of mTOR survival pathways [17-20]. Unfortunately both compounds are in short supply and very expensive.

Compared to the expensive procedure of synthesizing pure tocotrienols, the natural products, for example, palm oil, containing tocol-rich fractions, have been used to supply the radioprotective constituents. Rice bran oil deodorizer distillate (RBODD) is a by-product from the process of refining rice and is usually discarded. It is rich in tocols, including the active $\gamma$ - and $\delta$-tocotrienols. It also contains squalene, which has been shown to possess radioprotective capacity [21].

The objective of this research was to characterize the tocotrienol-rich fraction of rice bran (TRFRB) isolated from rice bran oil deodorizer distillate (RBODD) and investigate its protective effects against $\mathrm{H}_{2} \mathrm{O}_{2}$ and IR induced oxidative damage. We used various murine and human cells to assess the efficacy of TRFRB against IR injury by measuring cell morphology, lipid peroxidation, thiol oxidation, cellular bioenergetics and mitochondrial respiration, keratinocyte migration, cell cycle analysis, and clonogenic cell survival.

\section{Materials and Methods}

2.1. Cell Culture. H9c2 rat cardiomyocytes and immortalized human skin keratinocyte cell line (HaCaT) were kindly donated by Dr. Marsh (UAMS) and Dr. Domann (UIOWA), respectively. Primary human dermal fibroblasts were purchased from Lifeline Cell Technologies (Frederick, MD) and rat liver microsomes were purchased from BD Biosciences. All cell lines were grown in Dulbecco's Minimal Essential Medium containing high glucose and supplemented with $1 \mathrm{mM}$ sodium pyruvate (Gibco), 10\% FBS (HyClone), and $1 \%$ L-glutamine (Gibco) in the presence of $1 \%$ penicillin and streptomycin. Cells were maintained and experiments were accomplished in a humidified incubator at $37^{\circ} \mathrm{C}$ with $5 \%$ $\mathrm{CO}_{2}$. For mitochondrial respiration studies, culture media in cells were changed to unbuffered DMEM supplemented with $4 \mathrm{mM}$ glutamate and incubated in a non- $\mathrm{CO}_{2}$ incubator for $1 \mathrm{~h}$ at $37^{\circ} \mathrm{C}$, before they were placed in XF96 Extracellular Flux Analyzer. In all experiments, where DMSO was used as vehicle, its final concentration in the tissue culture dishes was kept at $0.1 \%$ or less $(\mathrm{v} / \mathrm{v})$.

2.2. Preparation of TRFRB (Tocotrienol-Rich Fraction of Rice Bran). TRFRB was prepared by rice bran oil deodorizer distillate (RBODD) by an adaptation of the method described by Ko et al. [22]. RBODD, provided by Riceland Foods (Stuttgart, AR), was refluxed with acetonitrile in a $1: 10$ ratio. After refluxing, samples were cooled to ambient temperature and stored at $-20^{\circ} \mathrm{C}$ for $24 \mathrm{~h}$ to precipitate the cold insoluble sterols from the soluble tocols. The sterols were filtered using a sintered glass filter, the filtrate was collected, and the solvent evaporated using a SpeedVac concentrator. Samples were then mixed with an ethanolic solution containing 5\% (w/v) pyrogallol and the mixture was refluxed to boiling. Tocols were saponified at $70^{\circ} \mathrm{C}$ for $30 \mathrm{~min}$ following the addition of $1 \mathrm{~mL}$ of $50 \%(\mathrm{w} / \mathrm{v})$ aqueous potassium hydroxide solution. After cooling in an ice water bath the mixture was transferred to a $500 \mathrm{~mL}$ separatory funnel, and $30 \mathrm{~mL}$ diethyl ether and $20 \mathrm{~mL}$ distilled water were added. The diethyl ether extraction was repeated two times and the ether fractions were pooled. The pooled diethyl ether was washed three times with $20 \mathrm{~mL}$ distilled water and then filtered through anhydrous sodium sulfate for $30 \mathrm{~min}$ to remove any excess water. The diethyl ether was evaporated using the SpeedVac concentrator to obtain the tocotrienol-rich fraction of rice bran (TRFRB).

2.3. Qualitative and Quantitative Analysis of TRFRB. Composition of TRFRB was determined by a gas chromatography/mass spectrometry (GC/MS) method. For this analysis, samples of the extract were analytically transferred to deactivated glass microinserts using methylene chloride, dried under nitrogen, and derivatized using $N$-methyl- $N$ TMS-trifluoroacetamide (Restek Co., Bellefonte, PA) at $25^{\circ} \mathrm{C}$. Analyses were performed by GC/MS using Agilent 5975 GC/MSD (Agilent Technologies, Santa Clara, CA). The GC was equipped with a $30 \mathrm{~m}$ HP-5MS column $(0.250 \mathrm{mM}$, $0.25 \mu \mathrm{M})$. Samples were analyzed using helium as the carrier gas (head pressure of $27 \mathrm{psi}$ ) and $1 \mu \mathrm{L}$ splitless injection; the injector temperature was $275^{\circ} \mathrm{C}$; the column temperature was maintained at $220^{\circ} \mathrm{C}$ for $2 \mathrm{~min}$ followed by a gradient of $25^{\circ} \mathrm{C} / \mathrm{min}$ to $300^{\circ} \mathrm{C}$, remaining at that temperature for $10 \mathrm{~min}$. The transfer line temperature was maintained at $285^{\circ} \mathrm{C}$ for $13.5 \mathrm{~min}$ followed by a gradient of $25^{\circ} \mathrm{C} / \mathrm{min}$ to $300^{\circ} \mathrm{C}$, remaining at that temperature for $10 \mathrm{~min}$. The $\mathrm{MS}$ conditions were as follows: electron impact, source temperature $230^{\circ} \mathrm{C}$, quadrupole temperature $150^{\circ} \mathrm{C}$, and ionization voltage $70 \mathrm{eV}$. The identity of the tocols in the rice extract was established by comparing the retention time and mass spectra of authentic samples of each tocol (Yasoo Health, Jonesborough, TN). Quantitation of the derivatized tocols was performed in triplicate using single-ion monitoring. The MS ions detected were 496.8 ( $\alpha$-tocotrienol), 502.9 ( $\alpha$-tocopherol), and 482.8 ( $\beta$ - $\gamma$-tocotrienol). The confirming ions were 237,237 , and 223 , respectively. All the bioassays were conducted using proper dilutions of stock solution of $76.2 \mathrm{mg} / \mathrm{mL}$ TRFRB in DMSO standardized to $20 \mathrm{mM}$ content of tocotrienols $(9.8 \mathrm{mM}$ of GT3/BT3 and $8.6 \mathrm{mM}$ of AT3).

2.4. TBARS Assay. The antioxidant activity of TRFRB was assessed measuring the ability to prevent microsomal lipid peroxidation. For this a TBARS assay was performed using a modified version of the original method described by Buege and Aust (1978). Briefly, rat liver microsomes (BD 
Biosciences) were suspended in PBS in glass tubes at a final concentration of $1 \mathrm{mg} / \mathrm{mL}$. To this, increasing concentrations of TRFRB dissolved in DMSO were added. DMSO alone was used as control. The final DMSO percentage was kept under $0.1 \%$. Microsomes were subsequently incubated with the test compounds at $37^{\circ} \mathrm{C}$ for one hour in a shaking water bath $(100 \mathrm{rpm})$. After one hour, freshly made tert-butyl hydroperoxide (TBHP) solution was added to microsomes at a final concentration of $200 \mu \mathrm{M}$ and incubation was continued for another $30 \mathrm{~min}$. The reaction was terminated by addition of $20 \%$ trichloroacetic acid and tubes were placed on ice for $15 \mathrm{~min}$. Equal volume of $0.67 \%$ thiobarbituric acid in $0.05 \mathrm{~N} \mathrm{NaOH}$ was added and the final mixture was heated at $95^{\circ} \mathrm{C}$ for $45 \mathrm{~min}$ to allow the color to develop. Finally, the tubes were cooled on ice and centrifuged at $1000 \mathrm{rpm}$ for $20 \mathrm{~min}$ and the supernatant was read at $532 \mathrm{~nm}$. The percent TBARS was calculated using a standard curve obtained using malondialdehyde (MDA). The results in Figure 2 are expressed in $\mu \mathrm{M}$ of tocotrienols and compared with the effects of pure gamma-tocotrienol [23].

2.5. Cell Morphology. H9c2 rat heart cardiomyocytes were treated with either vehicle control (DMSO, 0.1\% v/v), $5 \mu \mathrm{M}$ delta-tocotrienol, or $5 \mu \mathrm{M}$ TRFRB overnight. Cells were then exposed to 100 or $200 \mu \mathrm{M} \mathrm{H}_{2} \mathrm{O}_{2}$ for $4 \mathrm{~h}$. Morphological changes were recorded under an inverted microscope. Pictures were taken at 10x magnification. Scale bar represents $400 \mu \mathrm{m}$.

2.6. Mitochondrial Bioenergetics. Oxygen consumption rate (OCR) was measured at $37^{\circ} \mathrm{C}$ using an XF96 Extracellular Analyzer (Seahorse Bioscience) as previously described [24]. H9c2 rat heart cardiomyocytes cells were plated in 96-well Seahorse plates. The next day they were treated with either vehicle (DMSO, $0.1 \% \mathrm{v} / \mathrm{v}$ ) or $5 \mu \mathrm{M}$ of DT3 or $5 \mu \mathrm{M}$ of TRFRB overnight. The cells were then treated with 50 or $100 \mu \mathrm{M}$ $\mathrm{H}_{2} \mathrm{O}_{2}$ for $4 \mathrm{~h}$ at $37^{\circ} \mathrm{C}$. The media in the wells were changed to unbuffered DMEM supplemented with $4 \mathrm{mM}$ glutamate and incubated in a non- $\mathrm{CO}_{2}$ incubator for $1 \mathrm{~h}$ at $37^{\circ} \mathrm{C}$. Three baseline measurements were acquired before injection of mitochondrial inhibitors or uncouplers. Readings were taken after sequential addition of oligomycin $(10 \mu \mathrm{M})$, carbonylcyanide 4-(trifluoromethoxy)phenylhydrazone (FCCP, $10 \mu \mathrm{M}$ ), and rotenone/antimycin $\mathrm{A}(10 \mu \mathrm{M})$. Oxygen consumption rates were calculated by the Seahorse XF96 software and represent an average of 3 measurements on 8 different wells. The rate of measured oxygen consumption was reported as pmole $\mathrm{O}_{2}$ consumed per minute per 10,000 cells.

In order to determine the radioprotective effects of TRFRB, human immortalized keratinocytes (HaCaT cells) were plated in 96-well Seahorse plates. The next day they were treated with either vehicle (DMSO, $0.1 \% \mathrm{v} / \mathrm{v}$ ) or $5 \mu \mathrm{M}$ of DT3 or $5 \mu \mathrm{M}$ of TRFRB overnight. The Seahorse plates were either sham irradiated or irradiated with $8 \mathrm{~Gy}$ of $\gamma$ irradiation. Both plates were sequentially run in the XF96 Extracellular Analyzer as described above.

2.7. In Vitro Scratch Assay. Human immortalized keratinocytes (HaCaT cells) were plated in 12-well culture plates and irradiated with $8 \mathrm{~Gy}$ or sham irradiated $24 \mathrm{~h}$ after plating. The cells were given either vehicle (DMSO, $0.1 \% \mathrm{v} / \mathrm{v}$ ) or $5 \mu \mathrm{M}$ of DT3 or $5 \mu \mathrm{M}$ of TRFRB $4 \mathrm{~h}$ following radiation. Culture media were replaced again at $36 \mathrm{~h}$ following radiation. At the $72 \mathrm{~h}$ time point, a scratch was made using a sterile micropipette tip in each well. This created an open area into which the keratinocytes migrated. Two areas of the scratch margins were imaged daily until scratches were closed. The area of the scratch remaining was measured on the images at five points per field, with two fixed fields averaged using Cell Analyzer 1.0 (BWTech, Iowa City, IA). Measurements were stopped when cells no longer made positive progress towards the scratch origin [25].

2.8. Clonogenic Cell Survival. Human immortalized keratinocytes ( $\mathrm{HaCaT}$ cells) were plated and irradiated with $8 \mathrm{~Gy}$ or sham irradiated $24 \mathrm{~h}$ after plating. The cells were given either vehicle (DMSO, $0.1 \% \mathrm{v} / \mathrm{v}$ ) or $5 \mu \mathrm{M}$ of DT3 or $5 \mu \mathrm{M}$ of TRFRB $4 \mathrm{~h}$ following radiation. Culture media were replaced again at $36 \mathrm{~h}$ following radiation. At the $72 \mathrm{~h}$ time point, the cells were trypsinized and plated at various dilutions for clonogenic survival. Cells were fixed in $70 \%$ ethanol and stained with Coomassie Blue 14 d later. Clones with more than 50 cells were counted under dissecting microscope [26].

\subsection{Measurements of Glutathione and Glutathione Disulfide} Levels. Human dermal fibroblasts were plated in $100 \mathrm{~mm}$ plates and the next day they were treated with vehicle (DMSO, $0.1 \% \mathrm{v} / \mathrm{v}$ ) or $5 \mu \mathrm{M}$ of TRFRB for $16 \mathrm{~h}$. The cells were then irradiated with $8 \mathrm{~Gy}$. Cell pellets were collected $24 \mathrm{~h}$ following irradiation and pipette-homogenized in $50 \mathrm{mM} \mathrm{PO}_{4}$ buffer $\mathrm{pH} 7.8$ containing $1.34 \mathrm{mM}$ diethylenetriaminepentaacetic acid (DETAPAC buffer). Total glutathione content was determined as previously described using the Anderson method $[26,27]$. To distinguish reduced glutathione (GSH) and glutathione disulfide (GSSG), $2 \mu \mathrm{L}$ of a 1:1 mixture of 2vinylpyridine and ethanol was added per $30 \mu \mathrm{L}$ of sample and assayed as described previously [26, 28]. All glutathione determinations were normalized to the protein content of whole homogenates using the Lowry et al. method [29].

2.10. Cell Cycle Analysis. Human dermal fibroblasts were plated in $100 \mathrm{~mm}$ plates and the next day they were treated with vehicle (DMSO, $0.1 \% \mathrm{v} / \mathrm{v}$ ) or $5 \mu \mathrm{M}$ of TRFRB overnight. The cells were then irradiated with 2, 4, 6, or $8 \mathrm{~Gy}$. Cell pellets were collected $24 \mathrm{~h}$ following irradiation and fixed in $70 \%$ ethanol. Then the ethanol-fixed cells pellets were washed with PBS and treated with RNase A for $30 \mathrm{~min}$ followed by staining with propidium iodide $(35 \mu \mathrm{g} / \mathrm{mL})$. DNA content of propidium iodide-stained cells was analyzed by flow cytometry, and the percentage of cells in each phase of the cell cycle was calculated [2].

2.11. Statistical Analysis. Statistical analysis was performed using GraphPad Prism 5.0 (GraphPad Software, San Diego, California). Data were expressed as mean \pm SD unless otherwise specified. One-way ANOVA analysis with Tukey's post analysis was used to study the differences among 3 or 
TABLE 1: Chemical composition of TRFRB determined via GC/MS.

\begin{tabular}{lccc}
\hline Compound & Tocopherol & Tocotrienol & Others \\
\hline$\delta$-Tocopherol & 4.3 & & \\
$\beta$ - $\gamma$-Tocopherol & 11.7 & & \\
$\alpha$-Tocopherol & 9.3 & & \\
$\beta$ - $\gamma$-Tocotrienol & & 9.2 & \\
$\alpha$-Tocotrienol & & 8.1 & \\
Squalene & & & 31.2 \\
Campesterol & & & 3.2 \\
Sitosterol & & & 5.2 \\
Cycloartenol & & & 3.7 \\
2,4-Methylenecycloartenol & & 17.3 & 47.3 \\
\hline Total \% & 25.3 & & \\
\hline
\end{tabular}

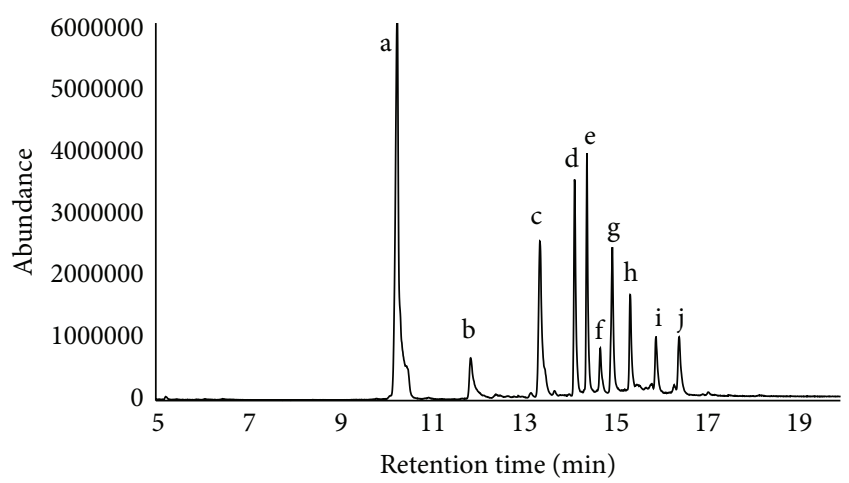

FIgURE 1: Composition of TRFRB determined by GC/MS. (a) Squalene, (b) $\delta$-tocopherol, (c) $\beta$ - and $\gamma$-tocopherol, (d) $\alpha$-tocopherol, (e) $\beta$ - and $\gamma$-tocotrienol, (f) campesterol, (g) $\alpha$-tocotrienol, (h) $\beta$ sitosterol, (i) cycloartenol, and (j) 2,4-methylenecycloartenol.

more means. Significance was determined at $p<0.05$ and the $95 \%$ confidence interval.

\section{Results}

A full scan GC/MS analysis demonstrated approximately $17.3 \%$ of tocotrienols, $25.3 \%$ of tocopherols, and $31.2 \%$ of squalene (Figure 1, Table 1).

In order to determine the $\mathrm{IC}_{50}$ for the antioxidant activity of TRFRB and GT3, the rat liver microsomes were pretreated with $0.5,1,5,10,50,100$, and $500 \mu \mathrm{M}$ of pure GT3 or TRFRB for $1 \mathrm{~h}$. The microsomes were then subjected to a powerful oxidant TBHP for an additional $30 \mathrm{~min}$. $\mathrm{IC}_{50}$ values for both are calculated as the concentration that reduced the amount of lipid peroxidation approximately $50 \%$. The $\mathrm{IC}_{50}$ values were $5.3 \mu \mathrm{M}$ and $10.3 \mu \mathrm{M}$ for pure GT3 and TRFRB, respectively, suggesting a comparable antioxidant capacity of TRFRB similar to pure GT3 against TBHB induced lipid peroxidation (Figure 2).

We then investigated whether TRFRB can protect the various cells types from different tissue origins against $\mathrm{H}_{2} \mathrm{O}_{2}$ or IR induced oxidative damage. Pretreatment of $\mathrm{H} 9 \mathrm{c} 2$ rat heart cardiomyocytes with $5 \mu \mathrm{M}$ of DT3 or TRFRB significantly protected the morphology of these cells from $4 \mathrm{~h}$ of 100 and $200 \mu \mathrm{M} \mathrm{H}_{2} \mathrm{O}_{2}$ treatment (Figure 3), suggesting that TRFRB

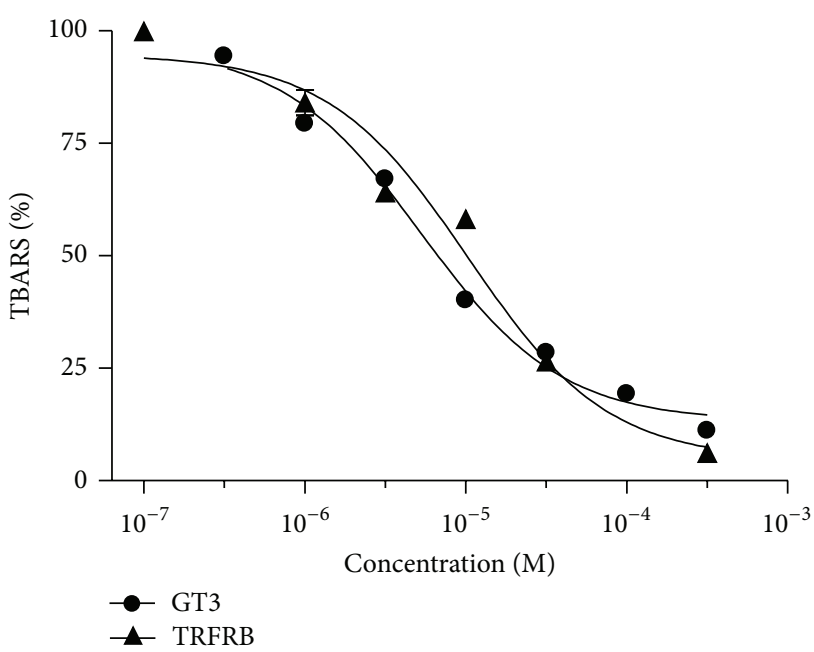

FIgURE 2: Comparative antioxidant activity of pure $\gamma$-tocotrienol (GT3) and TRFRB was determined by TBARS analysis.

is as effective as a pure tocotrienol isomer against peroxide induced cell injury.

We and others have previously shown that IR induced oxidative stress significantly and adversely affects mitochondrial electron transport chain and respiration [3, 7, 30]. Therefore, the next experiment assessed the effects of TRFRB and pure DT3 on cellular bioenergetics and mitochondrial respiration in the absence of any cellular stress. Intracellular mitochondrial function was examined by sequentially adding inhibitors of oxidative phosphorylation $[24,30]$. Initially we took 3 measurements to determine the "basal respiration" of the cells. Next, by injecting an inhibitor of mitochondrial ATP synthase (oligomycin), a decrease in oxygen consumption rate (OCR) was obtained and this decrease in OCR is termed as "ATP linked respiration." In order to determine the maximal respiration potential of the cells, FCCP, an uncoupler, was used. Immediately following FCCP injection, oxygen consumption increased and cells reached to their maximum respiration. Mitochondrial "reserve respiratory capacity" was calculated by subtracting the maximum OCR from the basal OCR. Overnight $(16 \mathrm{~h})$ treatment of both DT3 and TRFRB increased basal oxygen consumption rate (OCR) as well as maximum $\mathrm{OCR}$ in $\mathrm{H} 9 \mathrm{c} 2$ rat heart cardiomyocytes (Figure 4(a)). When H9c2 cells were treated with additional $4 \mathrm{~h}$ of $50 \mu \mathrm{M} \mathrm{H}_{2} \mathrm{O}_{2}$, the basal, the ATP linked, and maximum OCR were significantly decreased compared to the control group. $100 \mu \mathrm{M} \mathrm{H}_{2} \mathrm{O}_{2}$ treatment for $4 \mathrm{~h}$ completely halted the cellular respiration (Figures 4(b) and 4(c)). Treatment with $5 \mu \mathrm{M}$ of DT3 or TRFRB for $16 \mathrm{~h}$ prior to 50 or $100 \mu \mathrm{M}$ $\mathrm{H}_{2} \mathrm{O}_{2}$ resulted in complete protection and restored the mitochondrial respiration of these cells (Figures 4(b) and 4(c)).

Next we extended our findings into a different cell type and different cellular injury. Since therapeutic irradiation can result in significant skin injury, we focused on two different skin cell types to determine whether TRFRB can protect human skin cells from IR induced stress. First primary human dermal fibroblast (HDF) cells were irradiated 
DMSO
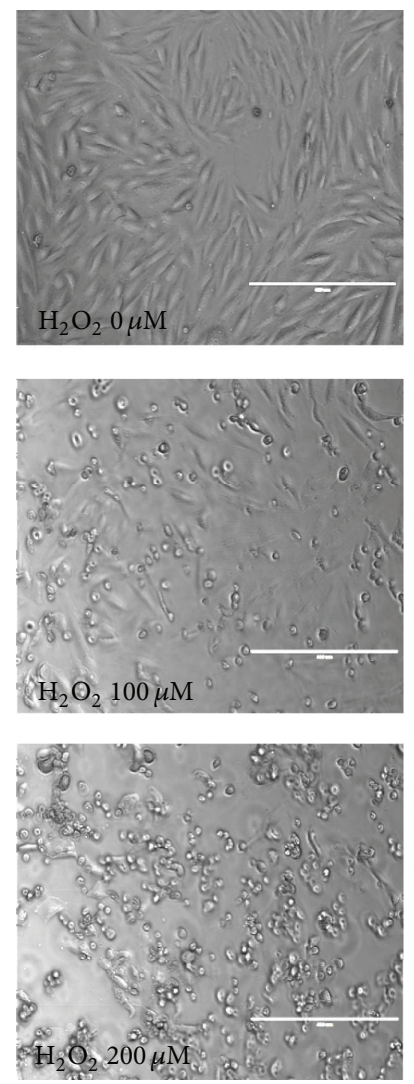

DT3
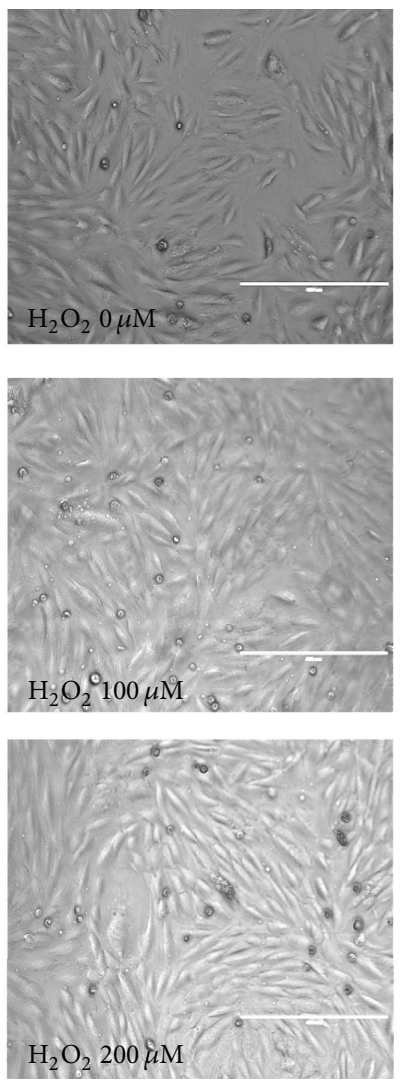

TRFRB
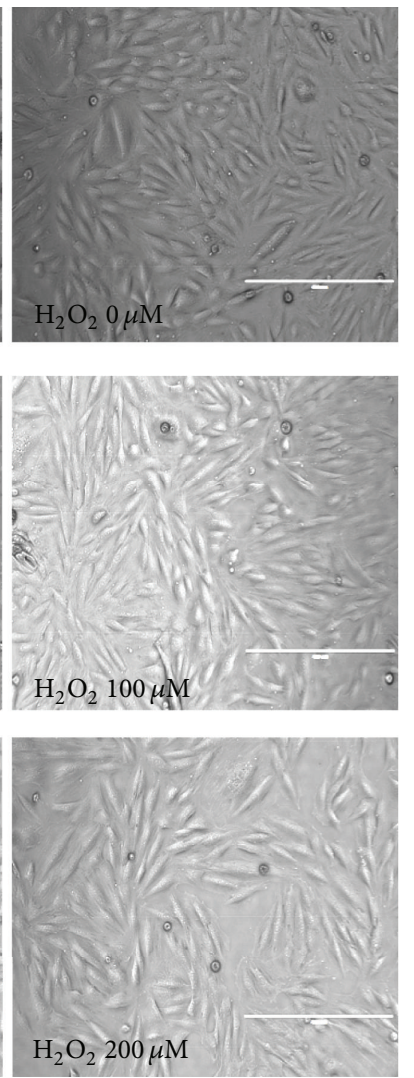

Figure 3: Pretreatment with $5 \mu \mathrm{M}$ DT3 or TRFRB significantly protected the cell morphology against $\mathrm{H}_{2} \mathrm{O}_{2}$ treatment. Pictures were taken at 10x magnification. The scale bar represents $400 \mu \mathrm{m}$.

at different doses and $24 \mathrm{~h}$ following IR the cells were collected to measure glutathione (GSH) and glutathione disulfide (GSSG) levels. Additional 2 sets of samples were also collected to be analyzed for cell cycle or replated for clonogenic cell survival assay. Both 4 and 8 Gy IR significantly increased the percentage of GSSG over total GSH suggesting an increase in oxidative stress in HDFs at these two IR doses. Pretreatment with $5 \mu \mathrm{M}$ TRFRB reversed this effect and significantly decreased the \% GSSG levels in HDFs (Figure 5(a)). TRFRB protection from IR induced oxidative stress was not extensive enough to improve HDF cells' reentry to the cell cycle (Figure 5(b)). TRFRB also did not protect HDFs from IR induced clonogenic cell killing from 2, 4, 6, or 8 Gy IR exposure (data not shown).

Secondly we utilized an immortalized human skin keratinocyte line ( $\mathrm{HaCaT}$ cells) to evaluate the radioprotective effects of TRFRB. HaCaT cells were pretreated with DMSO vehicle or $5 \mu \mathrm{M}$ of DT3 or TRFRB for $16 \mathrm{~h}$ prior to $8 \mathrm{~Gy}$ IR. Then the cellular bioenergetics and mitochondrial respiration in these cells were assayed at $48 \mathrm{~h}$ following IR exposure as described with $\mathrm{H} 9 \mathrm{c} 2$ cells. The percent mitochondrial uncoupling is defined and calculated by determining the increase in the ratio of basal respiration to maximum respiration (OCR following FCCP treatment) and the data was normalized to the sham irradiated control group. The degree of mitochondrial uncoupling of $\mathrm{HaCaT}$ cells was significantly increased at $48 \mathrm{~h}$ when exposed to $8 \mathrm{~Gy}$ IR and this increase was partially but significantly reversed in the presence of $5 \mu \mathrm{M}$ of DT3 or $5 \mu \mathrm{M}$ of TRFRB pretreatment (Figure 6).

In our next set of experiments we wanted to determine whether TRFRB could protect the skin cells from IR induced injury even if TRFRB is given after IR exposure. When HaCaT cells were irradiated with $8 \mathrm{~Gy}$ IR, received DMSO, $5 \mu \mathrm{M}$ of DT3, or $5 \mu \mathrm{M}$ of TRFRB $4 \mathrm{~h}$ after irradiation, and plated for clonogenic cell survival $72 \mathrm{~h}$ following IR, there was a slight increase in cell survival in both DT3 and TRFRB treated cells. This protection in the increased survival fraction provided by DT3 or TRFRB was not statistically significant compared to 8 Gy IR alone group (Figure 7). An in vitro scratch assay was utilized to evaluate the protective efficacy of TRFRB for keratinocyte migration function when the cells were treated with DMSO, $5 \mu \mathrm{M}$ of DT3, or $5 \mu \mathrm{M}$ of TRFRB after IR exposure. Migration rates of $\mathrm{HaCaT}$ cells were significantly improved (although they did not completely reach the levels of DMSO vehicle group) even if the cells were treated with DT3 or TRFRB $4 \mathrm{~h}$ after 8 Gy IR exposure (Figure 8 ).

\section{Discussion}

There is a significant and unmet need for the development of alternative strategies and novel agents to alleviate radiation side effects. The only approved radioprotective 


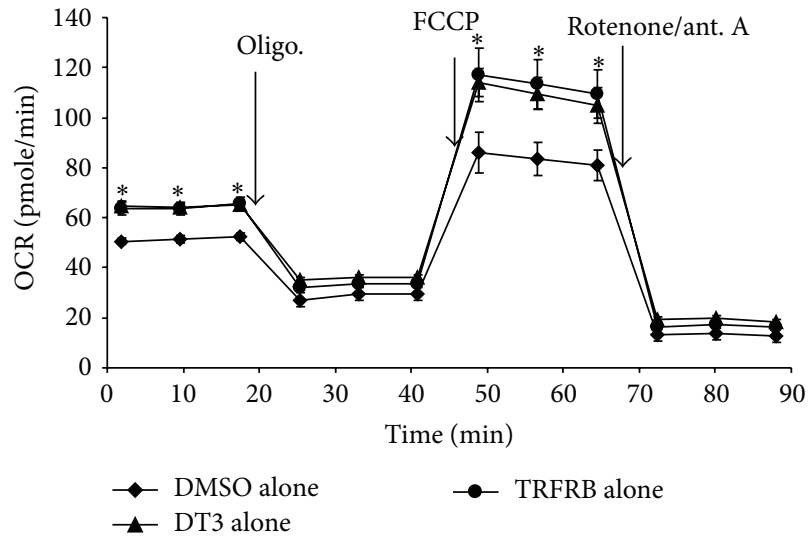

(a)

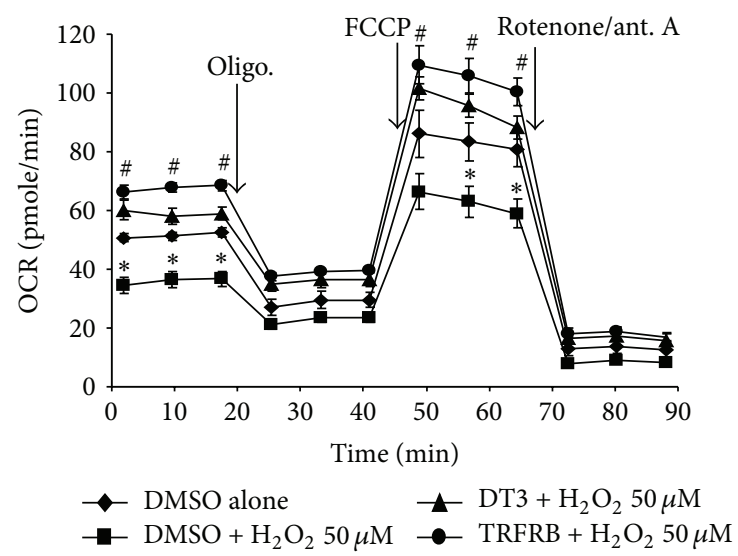

(b)

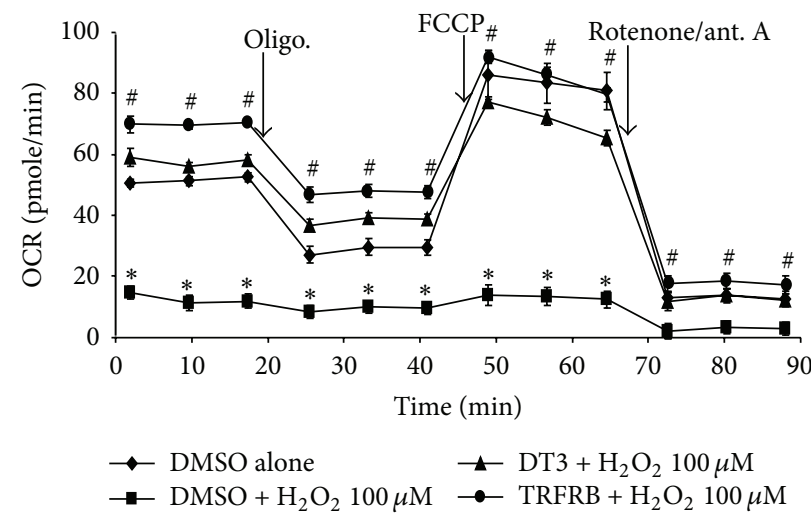

(c)

FIGURE 4: Pretreatment with $5 \mu \mathrm{M}$ DT3 or TRFRB preserved the cellular bioenergetics and mitochondrial respiration of H9c2 cells following $\mathrm{H}_{2} \mathrm{O}_{2}$ injury. Treatment of both DT3 and TRFRB increased basal oxygen consumption rate (OCR) as well as maximum OCR in H9c2 rat heart cardiomyocytes (a). Treatment with $5 \mu \mathrm{M}$ of DT3 or TRFRB prior to 50 (b) or $100 \mu \mathrm{M} \mathrm{H}_{2} \mathrm{O}_{2}$ (c) resulted in complete protection and restored the mitochondrial respiration. Each data point represents mean \pm SEM of $n=8-16$ wells from 2 separate experiments. ${ }^{*} p<0.01$ as compared to control, ${ }^{\#} p<0.001$ as compared to $\mathrm{H}_{2} \mathrm{O}_{2}$ treated group.

agent amifostine has limited use due to its side effects [31]. Tocotrienols, vitamin $\mathrm{E}$ analogs, have been gaining a great deal of attention in the past decade as radioprotectors for radiotherapy patients as well as in the context of accidental exposure of large populations. Their unsaturated isoprenoid side chain differentiates tocotrienols from tocopherols, which are less efficacious in protection against ionizing radiation. In addition to their antioxidant properties, the tocotrienols have been shown to increase tetrahydrobiopterin levels and thus increase eNOS activity. They also effectively inhibit 3hydroxy-3-methylglutaryl-coenzyme A (HMG-CoA) reductase enzyme, enhance hematopoietic recovery, reduce intestinal radiation injury, and accelerate the recovery of soluble markers of endothelial function [13, 17-20,32, 33]. Despite their superb radioprotective effects, however, tocotrienols (DT3 and GT3) are in short supply and very expensive to purify. It is in this context that a by-product of rice oil refinement could provide a viable alternative source for isolation of tocotrienols in large quantities.

Here we provide evidence that a tocotrienol-rich fraction of rice bran oil deodorizer distillate, TRFRB, shows efficacy against peroxide and ionizing radiation induced injury in vitro. TRFRB demonstrated a significant antioxidant function against hydroperoxide induced lipid peroxidation in rat liver microsomes, which was comparable to that of pure GT3.

Various cultured cell models were also utilized to explore which attributes of TRFRB were required for protection against $\mathrm{H}_{2} \mathrm{O}_{2}$ and IR induced cell damage in cardiomyocytes, epidermal keratinocytes, and dermal fibroblasts. TRFRB demonstrated a profound effect preserving the morphology of cardiomyocytes against $\mathrm{H}_{2} \mathrm{O}_{2}$ exposure. TRFRB also protected the human dermal fibroblasts cells from IR induced oxidative stress by preventing the oxidation of glutathione following IR exposure. However, the reversal of oxidation of this important thiol was not enough to protect the dermal fibroblasts from IR induced cytotoxicity determined by the clonogenic cell survival assay. Interestingly, epidermal keratinocytes treated with DT3 or TRFRB after irradiation demonstrated only a slight increase in clonogenic cell survival. These results suggest that tocotrienols may protect the overall redox homeostasis in the cells but they may not be sufficient to protect from other types of IR induced injuries 


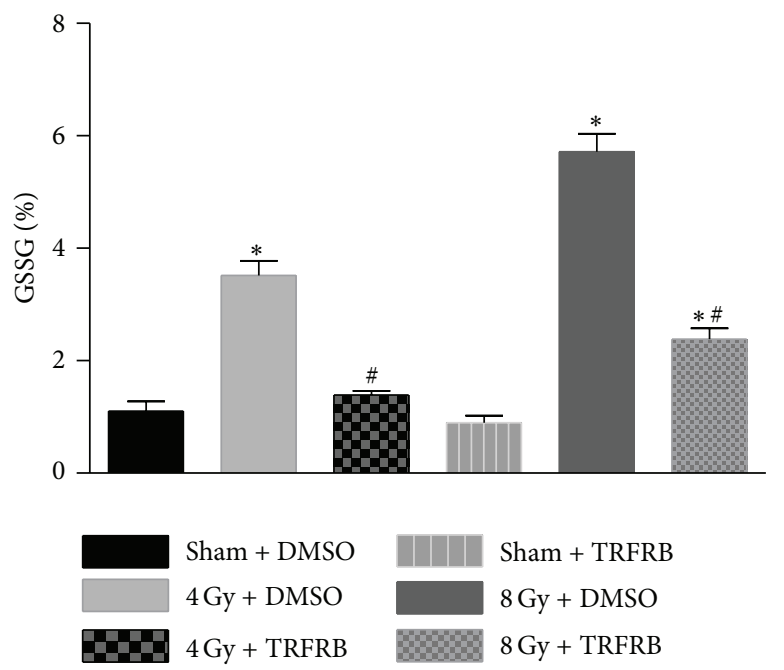

(a)

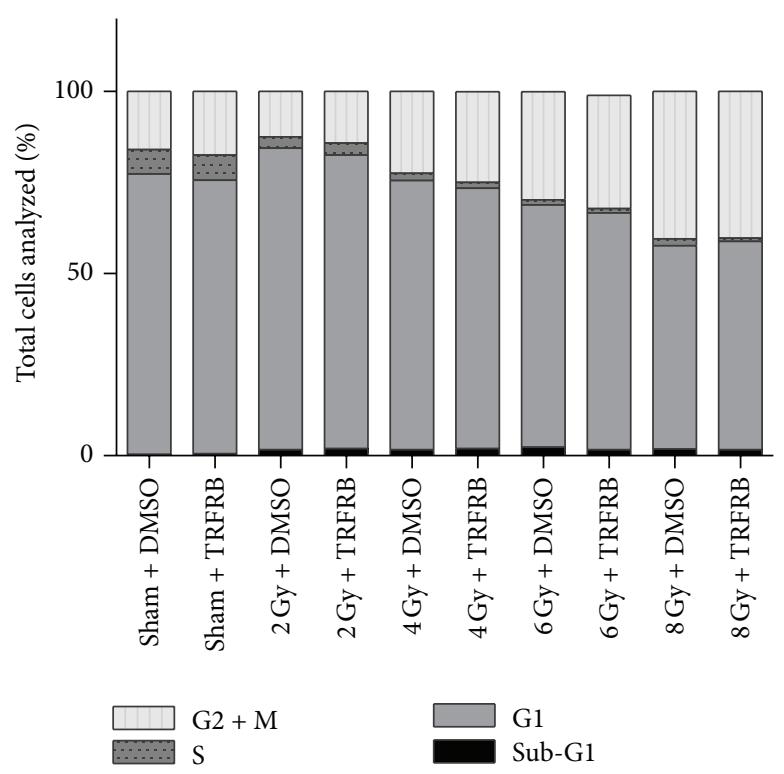

(b)

FIGURE 5: (a) Oxidized glutathione levels in dermal fibroblasts were increased at $72 \mathrm{~h}$ when the cells were exposed to 4 or 8 Gy IR. This increase was prevented when cells received $5 \mu \mathrm{M}$ TRFRB $24 \mathrm{~h}$ before IR. Each data point represents mean $\pm \mathrm{SD}$ of $n=3$ treatment dishes. ${ }^{*} p<0.001$ as compared to sham DMSO group, ${ }^{*} p<0.001$ as compared to IR treated group. (b) There was no significant change in these cells that received TRFRB for the cell cycle reentry in $24 \mathrm{~h}$ following $2,4,6$, or 8 Gy irradiation.

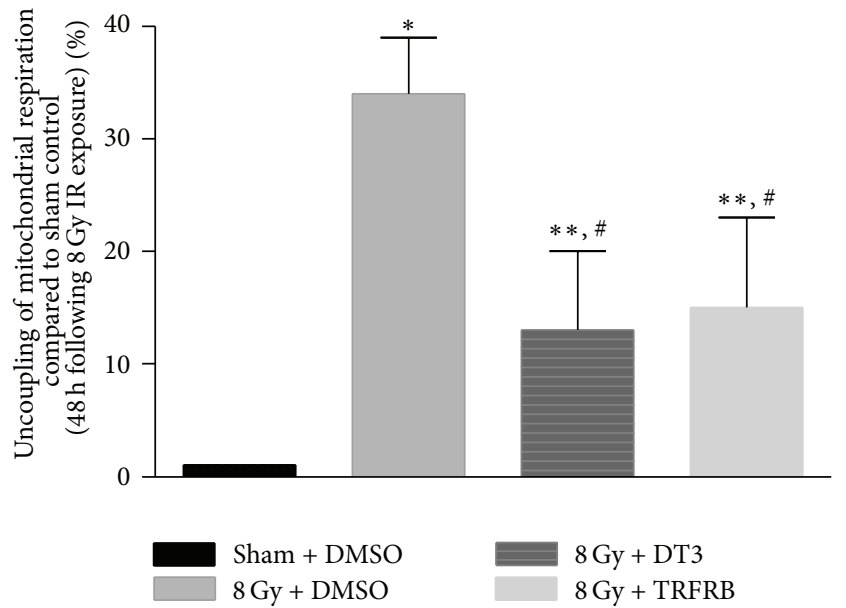

FIgURE 6: The degree of mitochondrial uncoupling of HaCaT cells was significantly increased at $48 \mathrm{~h}$ when exposed to $8 \mathrm{~Gy}$ IR and this increase was reversed in the presence of $5 \mu \mathrm{M}$ DT3 or TRFRB. Each data point represents mean \pm SEM of $n=8-16$ wells from 2 separate experiments. ${ }^{*} p<0.001$ as compared to sham DMSO group, ${ }^{* *} p<$ 0.05 as compared to sham DMSO group, and ${ }^{\#} p<0.05$ as compared to IR treated group.

in vitro (e.g., DNA damage, modulation of cell cycle proteins such as cyclin B1).

More importantly migration rates of keratinocytes were significantly improved by DT3 or TRFRB treatment even though they received TRFRB $4 \mathrm{~h}$ after exposure to IR. Additional DT3 or TRFRB treatment of these cells at $36 \mathrm{~h}$ following radiation exposure probably fortified and protected

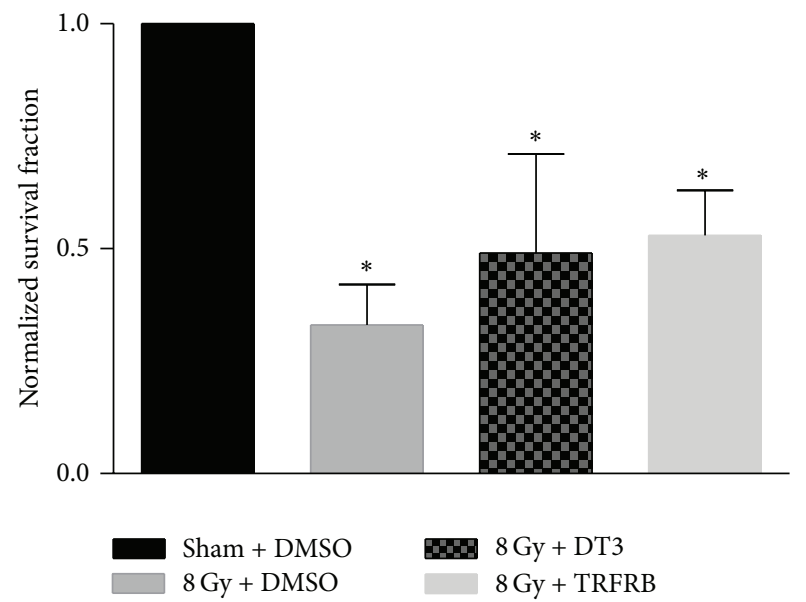

FIGURE 7: When HaCaT cells were irradiated with 8 Gy IR, received DT3 or TRFRB $4 \mathrm{~h}$ after irradiation, and plated for clonogenic cell survival $72 \mathrm{~h}$ following IR, there was an increase in cell survival in TRFRB treated cells. However, this increased survival fraction was not statistically significant compared to 8 Gy IR alone group. Each data point represents mean \pm SD of $n=3$ treatment dishes. ${ }^{*} p<$ 0.001 as compared to sham DMSO group.

the keratinocytes from IR induced late ROS effects. This is significant since keratinocyte migration is a crucial component of wound healing, which is known to be perturbed when skin is exposed to $\operatorname{IR}[34,35]$.

Our mitochondrial function and cellular respiration studies also revealed significant effects of TRFRB on cells with or without any cellular stress. Oxygen consumption rates of 

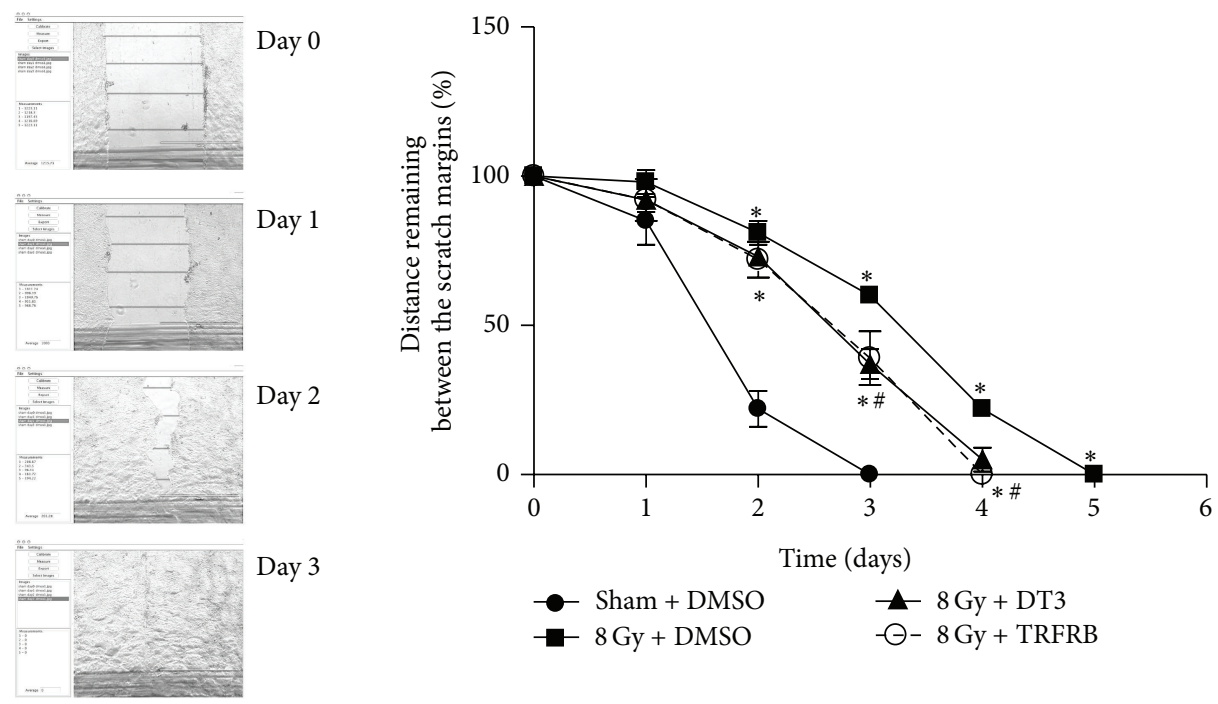

Figure 8: Migration rates of HaCaT cells were decreased when the cells were exposed to 8 Gy IR. This decrease was partially restored when cells received $5 \mu \mathrm{M}$ DT3 or TRFRB $4 \mathrm{~h}$ after IR exposure. Each data point represents mean \pm SD of five points per field, with two fixed fields $(n=10) .{ }^{*} p<0.01$ as compared to sham DMSO group, ${ }^{*} p<0.01$ as compared to IR treated group.

the cells were measured using the XF96 Extracellular Flux Analyzer. The increases measured in basal and maximal OCR suggest that both DT3 and TRFRB enhanced cellular respiration, which could be due to an increase in mitochondrial biogenesis or enhanced function of existing mitochondria. Our calculations also demonstrated an increase in reserve respiratory capacity of the cells implying that TRFRB and DT3 improve the ability to respond against any stress that might increase the energy demand in the cell. This supposition was validated when the cells were exposed to two powerful stressors, $\mathrm{H}_{2} \mathrm{O}_{2}$ or IR. In both cases, pretreatment of cardiomyocytes or skin keratinocytes with TRFRB exhibited significant protection of mitochondrial function.

Collectively these results strongly suggest that the antioxidant capacity of TRFRB was critical to its ability to protect cells from oxidative injuries (via $\mathrm{H}_{2} \mathrm{O}_{2}$ or IR). However, our cellular bioenergetics studies also allow for the speculation that TRFRB protects the cells against IR injury by partly preserving the cells' mitochondrial function. Our future studies will include investigation of the molecular mechanisms by which TRFRB exerts its radioprotective/mitigative effects in different cell types, as well as its efficacy against IR induced normal tissue injury in vivo.

\section{Conflict of Interests}

The authors declared no conflict of interests.

\section{Acknowledgments}

The authors would like to acknowledge the following funding sources: NIGMS P20 GM109005, NIEHS R15 ES022781, NCI R37 CA71382, NIAID U19 AI67798, NCI P30-CA051008, NASA-NSBRI RE0370, ASTA 15-B-19, UAMS Tobacco FY13, and the US Veterans Administration. ENP is a recipient of a graduate student scholarship from Ecuadors Higher Education, Science, and Technology Ministry (SENESCYT).

\section{References}

[1] D. Citrin, A. P. Cotrim, F. Hyodo, B. J. Baum, M. C. Krishna, and J. B. Mitchell, "Radioprotectors and mitigators of radiationinduced normal tissue injury," Oncologist, vol. 15, no. 4, pp. 360371, 2010.

[2] B. G. Slane, N. Aykin-Burns, B. J. Smith et al., "Mutation of succinate dehydrogenase subunit $\mathrm{C}$ results in increased $\mathrm{O}_{2}^{-}$, oxidative stress, and genomic instability," Cancer Research, vol. 66, no. 15, pp. 7615-7620, 2006.

[3] N. Aykin-Burns, B. G. Slane, A. T. Y. Liu et al., "Sensitivity to low-dose/low-let ionizing radiation in mammalian cells harboring mutations in succinate dehydrogenase subunit $\mathrm{C}$ is governed by mitochondria-derived reactive oxygen species," Radiation Research, vol. 175, no. 2, pp. 150-158, 2011.

[4] L. W. Oberley, L. A. Lindgren, S. A. Baker, and R. H. Stevens, "Superoxide lon as the cause of the oxygen effect," Radiation Research, vol. 68, pp. 320-328, 1976.

[5] J. E. Biaglow, J. B. Mitchell, and K. Held, "The importance of peroxide and superoxide in the X-ray response," International Journal of Radiation Oncology, Biology, Physics, vol. 22, no. 4, pp. 665-669, 1992.

[6] A. Petkau, W. S. Chelack, and S. D. Pleskach, "Letter: protection of post-irradiated mice by superoxide dismutase," International Journal of Radiation Biology and Related Studies in Physics, Chemistry, and Medicine, vol. 29, pp. 297-299, 1976.

[7] D. Dayal, S. M. Martin, K. M. Owens et al., "Mitochondrial complex II dysfunction can contribute significantly to genomic instability after exposure to ionizing radiation," Radiation Research, vol. 172, no. 6, pp. 737-745, 2009.

[8] J. F. Weiss and M. R. Landauer, "History and development of radiation-protective agents," International Journal of Radiation Biology, vol. 85, pp. 539-573, 2009. 
[9] F. Dumont, A. Le Roux, and P. Bischoff, "Radiation countermeasure agents: an update," Expert Opinion on Therapeutic Patents, vol. 20, no. 1, pp. 73-101, 2010.

[10] K. Anzai, N. Ban, T. Ozawa, and S. Tokonami, "Fukushima daiichi nuclear power plant accident: facts, environmental contamination, possible biological effects, and countermeasures," Journal of Clinical Biochemistry and Nutrition, vol. 50, no. 1, pp. 2-8, 2012.

[11] R. A. Larche, Global Terrorism Issues and Developments, Nova Science Publishers, New York, NY, USA, 2008, http://www.loc .gov/catdir/toc/fy0804/2007030869.html.

[12] B. Tan, R. R. Watson, and V. R. Preedy, Tocotrienols: Vitamin E beyond Tocopherols, CRC Press, Boca Raton, Fla, USA, 2nd edition, 2013.

[13] V. K. Singh, S. Y. Wise, O. O. Fatanmi et al., "Progenitors mobilized by gamma-tocotrienol as an effective radiation countermeasure," PLoS ONE, vol. 9, no. 11, Article ID e114078, 2014.

[14] V. K. Singh, E. J. Ducey, D. S. Brown, and M. H. Whitnall, "A review of radiation countermeasure work ongoing at the armed forces radiobiology research institute," International Journal of Radiation Biology, vol. 88, no. 4, pp. 296-310, 2012.

[15] V. K. Singh, L. A. Beattie, and T. M. Seed, "Vitamin E: tocopherols and tocotrienols as potential radiation countermeasures," Journal of Radiation Research, vol. 54, no. 6, pp. 973-988, 2013.

[16] V. Viola, F. Pilolli, M. Piroddi et al., "Why tocotrienols work better: insights into the in vitro anti-cancer mechanism of vitamin E," Genes \& Nutrition, vol. 7, no. 1, pp. 29-41, 2012.

[17] M. Berbe, Q. Fu, M. Boerma, J. Wang, K. S. Kumar, and M. Hauer-Jensen, " $\gamma$-Tocotrienol ameliorates intestinal radiation injury and reduces vascular oxidative stress after total-body irradiation by an HMG-CoA Reductase-dependent mechanism," Radiation Research, vol. 171, no. 5, pp. 596-605, 2009.

[18] M. Berbée, Q. Fu, M. Boerma, K. S. Kumar, D. S. Loose, and M. Hauer-Jensen, "Mechanisms underlying the radioprotective properties of $\gamma$-tocotrienol: comparative gene expression profiling in tocol-treated endothelial cells," Genes and Nutrition, vol. 7, no. 1, pp. 75-81, 2012.

[19] M. Berbee, Q. Fu, M. Boerma et al., "Reduction of radiationinduced vascular nitrosative stress by the vitamin e analog gamma-tocotrienol: evidence of a role for tetrahydrobiopterin," International Journal of Radiation Oncology Biology Physics, vol. 79, no. 3, pp. 884-891, 2011.

[20] M. Satyamitra, P. Ney, J. Graves III, C. Mullaney, and V. Srinivasan, "Mechanism of radioprotection by $\delta$-tocotrienol: pharmacokinetics, pharmacodynamics and modulation of signalling pathways," British Journal of Radiology, vol. 85, no. 1019, pp. e1093-e1103, 2012.

[21] H. M. Storm, S. Y. Oh, B. F. Kimler, and S. Norton, "Radioprotection of mice by dietary squalene," Lipids, vol. 28, no. 6, pp. 555-559, 1993.

[22] S.-N. Ko, S.-M. Lee, and I.-H. Kim, “The concentration of tocols from rice bran oil deodorizer distillate using solvent," European Journal of Lipid Science and Technology, vol. 110, no. 10, pp. 914919, 2008 .

[23] J. A. Buege and S. D. Aust, "Microsomal lipid peroxidation," Methods in Enzymology, vol. 52, pp. 302-310, 1978, http://www .ncbi.nlm.nih.gov/pubmed/672633.

[24] R. Pathak, S. A. Pawar, Q. Fu et al., "Characterization of transgenic Gfrp knock-in mice: implications for tetrahydrobiopterin in modulation of normal tissue radiation responses,"
Antioxidants and Redox Signaling, vol. 20, no. 9, pp. 1436-1446, 2014.

[25] C. Ross, M. Alston, J. R. Bickenbach, and N. Aykin-Burns, "Oxygen tension changes the rate of migration of human skin keratinocytes in an age-related manner," Experimental Dermatology, vol. 20, no. 1, pp. 58-63, 2011.

[26] N. Aykin-Burns, I. M. Ahmad, Y. Zhu, L. W. Oberley, and D. R. Spitz, "Increased levels of superoxide and $\mathrm{H}_{2} \mathrm{O}_{2}$ mediate the differential susceptibility of cancer cells versus normal cells to glucose deprivation," Biochemical Journal, vol. 418, no. 1, pp. 2937, 2009.

[27] R. A. Greenwald, CRC Handbook of Methods for Oxygen Radical Research, CRC Press, Boca Raton, Fla, USA, 1985.

[28] O. W. Griffith, "Determination of glutathione and glutathione disulfide using glutathione reductase and 2-vinylpyridine," Analytical Biochemistry, vol. 106, no. 1, pp. 207-212, 1980.

[29] O. H. Lowry, N. J. Rosebrough, A. L. Farr, and R. J. Randall, "Protein measurement with the Folin phenol reagent," The Journal of Biological Chemistry, vol. 193, no. 1, pp. 265-275, 1951.

[30] V. Sridharan, N. Aykin-Burns, P. Tripathi et al., "Radiationinduced alterations in mitochondria of the rat heart," Radiation Research, vol. 181, no. 3, pp. 324-334, 2014.

[31] M. I. Koukourakis, G. Kyrias, S. Kakolyris et al., "Subcutaneous administration of amifostine during fractionated radiotherapy: a randomized phase II study," Journal of Clinical Oncology, vol. 18, no. 11, pp. 2226-2233, 2000.

[32] M. Berbee, Q. Fu, K. S. Kumar, and M. Hauer-Jensen, "Novel strategies to ameliorate radiation injury: a possible role for tetrahydrobiopterin," Current Drug Targets, vol. 11, pp. 13661374, 2010.

[33] M. Berbée, Q. Fu, S. Garg, S. Kulkarni, K. S. Kumar, and M. Hauer-Jensen, "Pentoxifylline enhances the radioprotective properties of $\gamma$-tocotrienol: differential effects on the hematopoietic, gastrointestinal and vascular systems," Radiation Research, vol. 175, no. 3, pp. 297-306, 2011.

[34] N. Salvo, E. Barnes, J. van Draanen et al., "Prophylaxis and management of acute radiation-induced skin reactions: a systematic review of the literature," Current Oncology, vol. 17, no. 4, pp. 94$112,2010$.

[35] M. McQuestion, "Evidence-based skin care management in radiation therapy: clinical update," Seminars in Oncology Nursing, vol. 27, no. 2, pp. el-el7, 2011. 


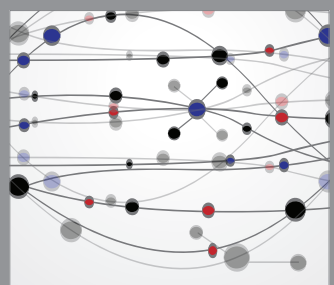

The Scientific World Journal
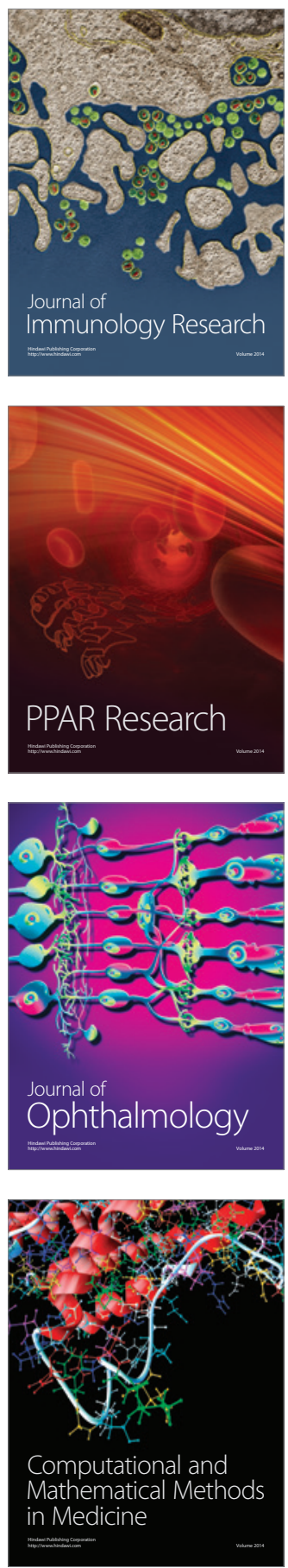

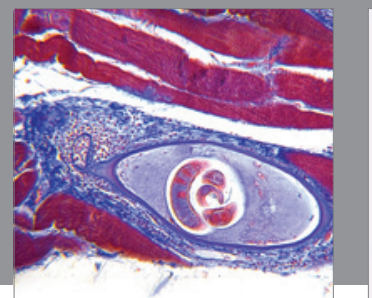

Gastroenterology

Research and Practice
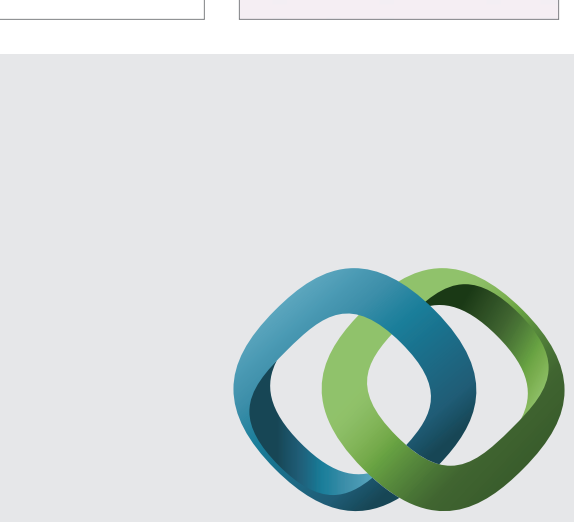

\section{Hindawi}

Submit your manuscripts at

http://www.hindawi.com
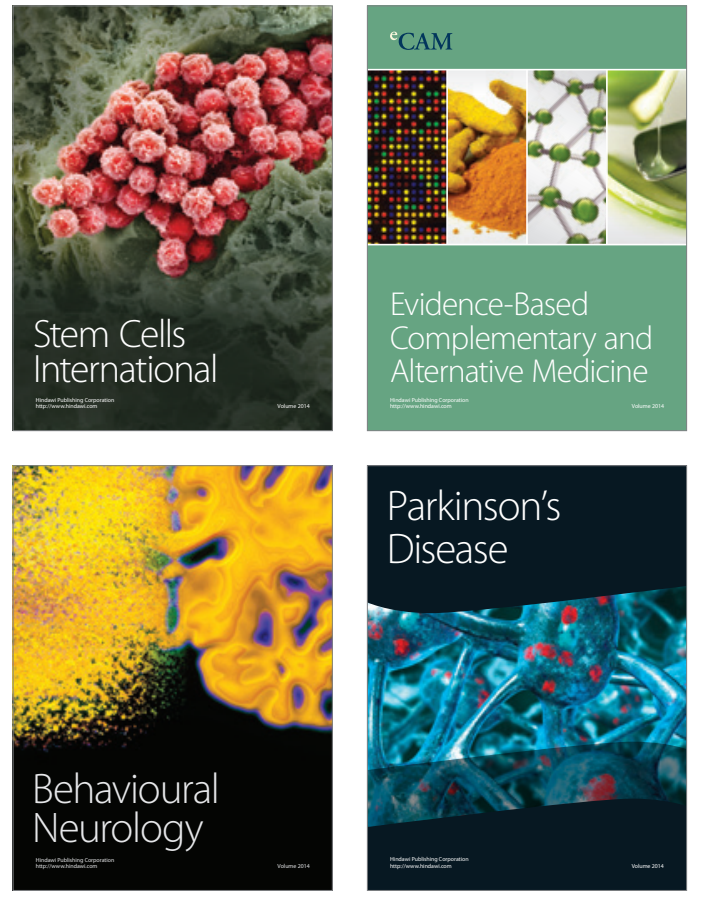
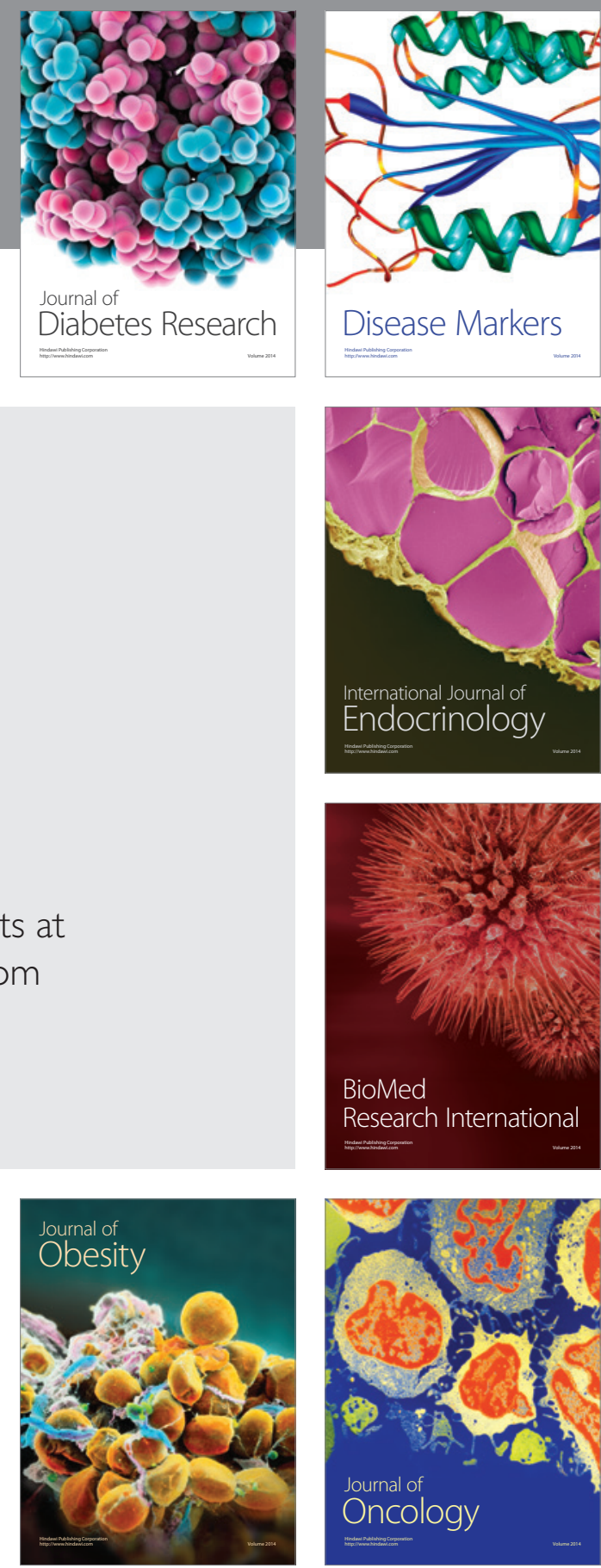

Disease Markers
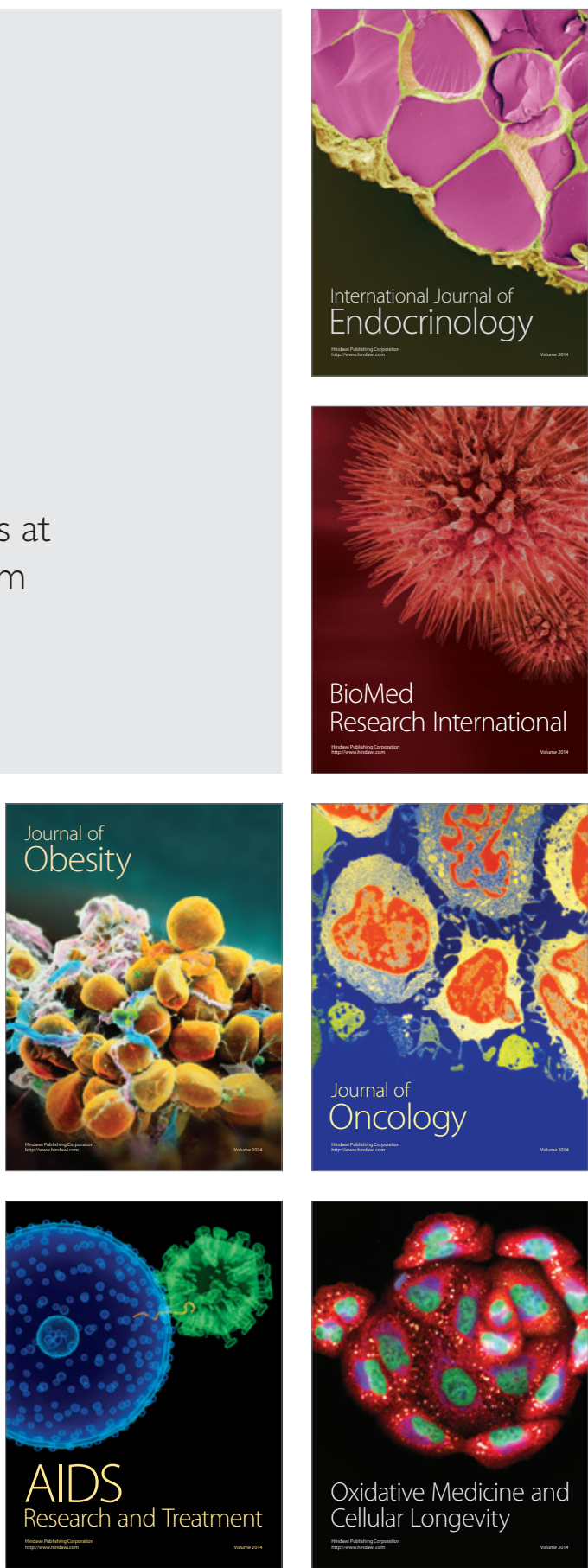